Article

\title{
Fatigue Behaviour of CFRP Strengthened Out-of-Plane Gusset Welded Joints with Double Cracks
}

\author{
Qian-Qian Yu, Tao Chen *, Xiang-Lin Gu and Ning-Xi Zhang \\ Department of Structural Engineering, Tongji University, Siping Road, 200092 Shanghai, China; \\ E-Mails: 2009_yuqianqian@tongji.edu.cn (Q.-Q.Y.); gxl@tongji.edu.cn (X.-L.G.); \\ 1431989@tongji.edu.cn (N.-X.Z.) \\ * Author to whom correspondence should be addressed; E-Mail: t.chen@tongji.edu.cn; \\ Tel./Fax: +86-21-6598-2928.
}

Academic Editors: Alper Ilki and Masoud Motavalli

Received: 22 July 2015 / Accepted: 31 August 2015 / Published: 7 September 2015

\begin{abstract}
This paper investigates the fatigue behaviour of out-of-plane gusset welded joints strengthened with carbon fibre reinforced polymer (CFRP) laminates. Two notches were introduced at the weld toes adjacent to longitudinal plate ends to simulate the initial damage. Variables including the stress range, single- or double-sided strengthening and modulus of CFRP materials were considered. It was found that both cracks propagated under fatigue loading. All the specimens fractured along one predefined notch when the fatigue crack reached a certain length while the other crack also grew to some extent. Test results showed that the addition of composite materials significantly prolonged the fatigue life of specimens by as much as 1.28 to 8.17 times. Double-sided bond and ultra-high modulus CFRP materials led to a better strengthening efficiency. Thereafter, a series of numerical analyses were performed to study the stress intensity factor (SIF) and crack opening displacement (COD). Local debonding around the crack tip at the adhesive-steel interface was taken into consideration. Finally, the fatigue life of all the specimens was evaluated based on the linear elastic fracture mechanism (LEFM) theory and the predicted results agreed well with the experimental data.
\end{abstract}

Keywords: CFRP; crack opening displacement; fatigue test; out-of-plane gusset welded joint; strengthening; stress intensity factor 


\section{Introduction}

Due to the combined effect of loading and environmental conditions, structural members are observed to deteriorate during their service life. For steel structures, fatigue cracks may emanate and grow in areas of stress concentration and even cause catastrophic accidents. In comparison with replacement, structural retrofitting provides an environmentally friendly and economic way to save and utilise the infrastructure, and, therefore, has become one of the primary interests in civil engineering community.

Recently, the bonded carbon fibre reinforced polymer (CFRP) approach in fatigue crack repair of steel structures has attracted much attention due to its outstanding physical and mechanical properties [1-3]. Extensive research has been carried out on CFRP bonded steel plates to evaluate the strengthening efficiency of this repair technique. Experimental results demonstrated that CFRP materials could effectively extend fatigue life and retard crack propagation of defective specimens, and the retrofitting efficiency was highly dependent on bond configuration, CFRP stiffness, prestress level and initial damage degree [4-9]. Stress intensity factor (SIF) at crack tip and fatigue crack propagation have also been studied numerically, where parametric analysis was performed to optimise this strengthening method [10-14]. In addition to research on retrofitting damaged steel plates, research on strengthening steel beams has also been conducted [15-24]. Ghafoori et al. [19-21] developed a prestressed unbonded reinforcement system for strengthening metallic beams. Fatigue design criteria for strengthening metallic beams with CFRP materials were also proposed $[23,24]$, which extended the understanding of CFRP-repaired steel beams.

However, studies on the fatigue behaviour of welded joints strengthened by CFRP materials are less reported. Generally, welded joints are vulnerable to fatigue damage due to weld-induced imperfections and stress gradient produced by geometric discontinuity.

Xiao and Zhao [25] conducted a constant amplitude fatigue experiment on thin-walled cross-beam connections bonded by CFRP sheets. Results showed that it was necessary to prevent early debonding in the corner and detailed configurations were presented. The flexural stiffness and fatigue life of the specimen was significantly increased after strengthening. Chen et al. [26] presented an experimental and numerical investigation on the fatigue behaviour of non-load-carrying cruciform welded joints. Analysis on stress concentration factor (SCF) revealed that CFRP overlays helped to decrease local stress field at the weld toe, which resulted in an increased fatigue life. In studies by Koller et al. [27,28], this repair technique was applied to a practical engineering of an artwork pendulum, where severe fatigue cracks developed in the heat-affected zone of the box welds after 19 months of service. Prestressed CFRP laminates were attached to the tension and compression flanges of the steel box girder and the cracks were successfully arrested. Suggestions to select suitable adhesive system for achieving high creep and fatigue strength of prestressed CFRP materials were also proposed.

Regarding out-of-plane gusset welded joints, Nakamura et al. [29] discussed repair methods of fatigue cracks initiated at welded web gusset joints and found that the combination of CFRP strips and drill-holes led to a considerable improvement in fatigue behaviour. The effect of bond layers was also confirmed with five layers deemed as the number required for a sufficient repair. More recently, Wu et al. [30] tested steel plates with longitudinal weld attachments on one side, with a particular focus on the application of ultra-high modulus CFRP materials and the influence of strengthening scheme. The fatigue life of the welded joints retrofitted on a single side was increased up to $141 \%$ over control ones. Wang and 
Wang [31] considered welded joints with corrugated plates. The effects of number and layout of CFRP sheets were examined. It was demonstrated that single-sided strengthening in the transition curvature region brought about a longer fatigue life in comparison with full width attachment on both sides of the main plate.

In general, all the above studies reported that CFRP strengthening extended the fatigue life and decreased crack propagation rate. Few researchers have attempted to perform numerical simulation on welded joints strengthened with CFRP materials [26,32-34]. Chen et al. [26,32,33] established finite element models and boundary element models of non-load-carrying cruciform welded joints. SCF and SIF were analysed to evaluate the strengthening efficiency. Yu et al. [34] investigated fatigue crack propagation of steel plates with longitudinal weld attachments strengthened by CFRP laminates on one side using the boundary element method. The effects of bond configuration, weld attachment and CFRP stiffness were considered. To the best knowledge of the authors, there have no attempt to perform a fatigue analysis using numerical simulation on out-of-plane gusset welded joints with two cracks strengthened with composite materials. This paper tested eight out-of-plane gusset welded joints under tensile fatigue loading, and variables including the stress range, single- or double-sided strengthening and modulus of CFRP laminates were considered. The finite element method was employed to investigate the SIF and crack opening displacement (COD) for all test specimens. Finally, the fatigue life was predicted based on the numerical results by the linear elastic fracture mechanism (LEFM) theory.

\section{Experimental Program}

The authors conducted a preliminary study on out-of-plane gusset welded joints strengthened by CFRP materials. This paper is an extension of the work reported by Chen et al. [35] in terms of (a) initial damage; (b) CFRP strengthening schemes; (c) CFRP modulus.

\subsection{Configuration of Test Specimens}

Specimens were made of a main plate $(700 \mathrm{~mm} \times 80 \mathrm{~mm} \times 8 \mathrm{~mm})$ with two gusset plates $(100 \mathrm{~mm} \times 80 \mathrm{~mm} \times 8 \mathrm{~mm})$, as shown in Figure 1. It was fabricated using $\mathrm{CO}_{2}$ gas shield fillet welding and kept in an as-welded condition. Dispersion of fatigue behaviour was observed from the previous experimental study due to the scatter nature of weld toe geometry. Therefore, two notches composed of a centre hole of $5 \mathrm{~mm}$ in diameter and two slots of $1 \mathrm{~mm}$ long were introduced at the weld toes to simulate the initial damage. The main purpose is to achieve an approximate initial state for both control specimens and strengthened specimens, so that the scatter effect on strengthening could be minimised (Figure 1b). The specimens were strengthened by CFRP laminates with a width of $25 \mathrm{~mm}$ and a length of $250 \mathrm{~mm}$. Both double-sided repair and single-sided repair were considered to investigate the effect of CFRP configuration on the strengthening efficiency, as shown in Figure 1c,d. 


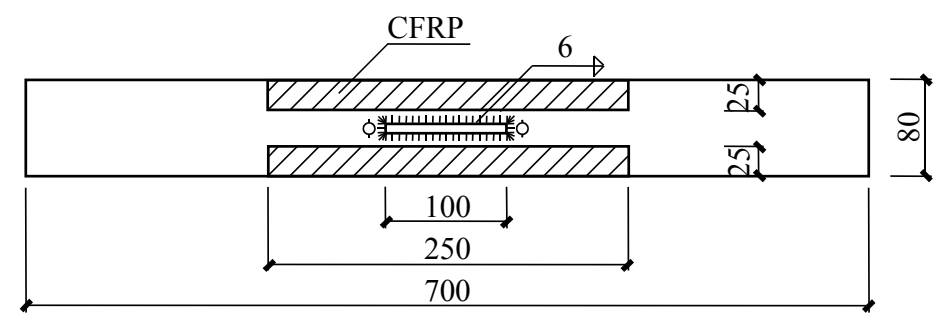

(a)

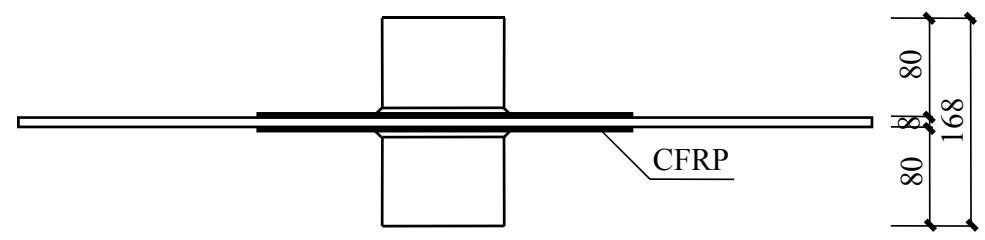

(c)

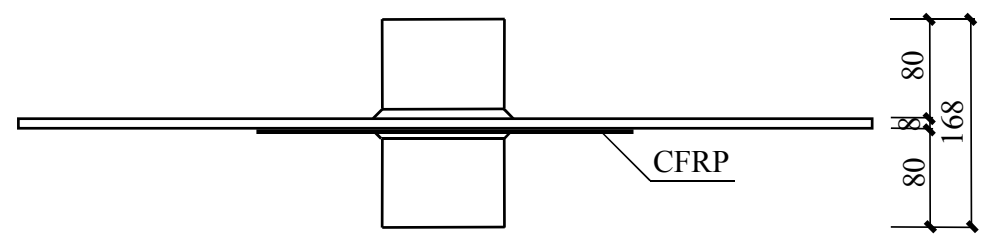

(d)

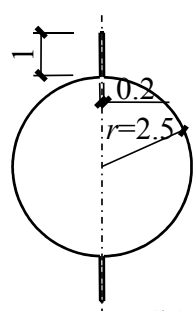

(b)

Figure 1. (a) Specimen geometry and dimensions (unit: $\mathrm{mm}$, not to scale); (b) Initial notch;

(c) Double-sided strengthened specimen; (d) Single-sided strengthened specimen.

\subsection{Material Properties}

Grade Q345 steel plates (according to Chinese Standard GB 50017-2003 [36]) were used in the experiment. A yield strength of $273 \mathrm{MPa}$ and an ultimate strength of $437 \mathrm{MPa}$ with an elastic modulus of $227 \mathrm{GPa}$ were determined through tensile coupon tests (mean values) [37]. Two types of laminates with the same nominal thickness of $1.2 \mathrm{~mm}$, i.e., CFC3-1.2-50 and Carbolam ${ }^{\circledR}$ THM450 $50 \times 1.2$, were selected in the test program. Based on the manufacturer's data sheet (characteristic values), CFC3-1.2-50 has a tensile modulus of $166 \mathrm{GPa}$, a tensile strength of $2516 \mathrm{MPa}$, and an ultimate elongation at break of 1.7\%. Carbolam ${ }^{\circledR}$ THM450 $50 \times 1.2$ has a tensile modulus of $460 \mathrm{GPa}$, a tensile strength of $1500 \mathrm{MPa}$, and an ultimate elongation at break of 0.34\%. Consequently, CFC3-1.2-50 and Carbolam ${ }^{\circledR}$ THM450 $50 \times 1.2$ are referred to as normal modulus CFRP and ultra-high modulus CFRP, respectively, in this paper. Structural adhesive, Araldite 420, was used to bond the composite overlays. Its measured tensile modulus and ultimate strength were 1.901 GPa and 28.6 MPa, respectively (mean values) [38]. It was revealed by Nguyen et al. $[39,40]$ that the glass transition temperature $T_{\mathrm{g}}$ of Araldite 420 was $42{ }^{\circ} \mathrm{C}$, and the bond behaviour decreased significantly as the temperature reached above $T_{\mathrm{g}}$. Therefore, this study focused on the fatigue behaviour of strengthened welded joints under $T_{\mathrm{g}}$. More research is needed to investigate the cases under combined fatigue and thermal loadings.

\subsection{Specimen Preparation}

The bond areas of the welded joints were first sandblasted to remove any weak layers and then were wiped using acetone to remove grease and other contaminates. For the ultra-high modulus CFRP laminate, a peel-ply was removed prior to bonding to ensure a clean and fresh surface; for the normal 
modulus CFRP laminate which did not contain a peel-ply, it was cleaned using acetone [41]. The adhesive layer is considered to be the weakest part, and therefore, bonding behaviour plays an important role in a strengthening system. The bond layer thickness was restricted to around $0.5 \mathrm{~mm}[42,43]$. Finally, the specimens were cured for two weeks at room temperature.

\subsection{Fatigue Loading}

The test program was conducted on an MTS 322 servo hydraulic testing machine. All the specimens were tested under tensile cyclic loading with a frequency of $10 \mathrm{~Hz}$ and a stress ratio $R$ (minimum load/maximum load) of 0.1. The test set-up is shown in Figure 2. Two scenarios were selected where the maximum loads were $85.3 \mathrm{kN}$ and $108.8 \mathrm{kN}$. The corresponding stress ranges in the nominal section of a control specimen were $120 \mathrm{MPa}$ and $153 \mathrm{MPa}$, respectively.

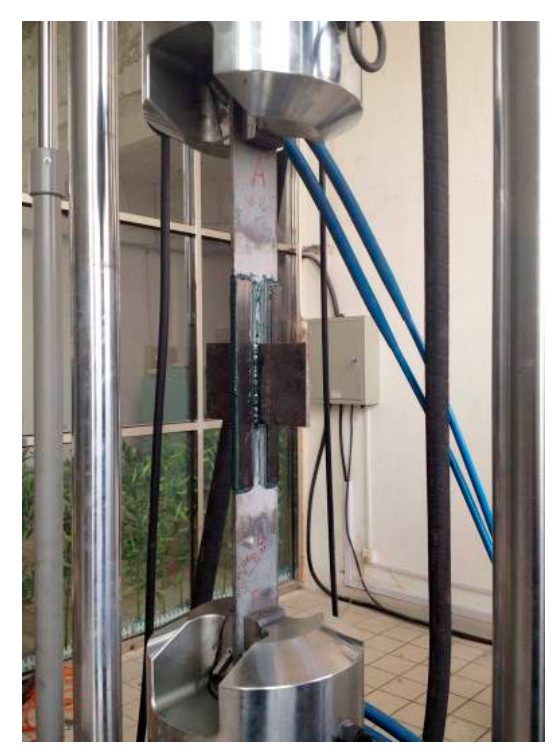

Figure 2. Test set-up.

It is essential to monitor crack propagation during the test to analyse fatigue behaviour. Therefore, the "beach marking" technique was adopted as shown in Figure 3. Fatigue cycles of a low stress range were inserted into the original load spectrum. In this way, the crack growth rate was changed that visible beach marks were left on the fracture surface of the specimens. Here, the load frequency and maximum load were kept constant, while the stress ratio was increased from 0.10 to 0.55 . 


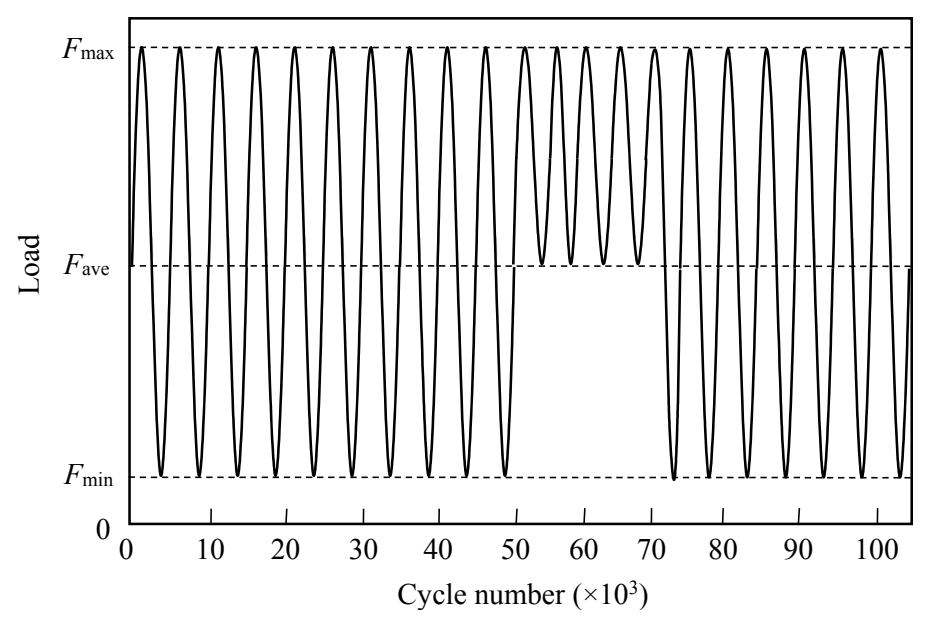

Figure 3. Load spectrum of the "beach marking" technique.

\section{Experimental Results}

A total of eight welded joints were designed, of which two were not repaired as control specimens. The detailed test program and results are listed in Table 1. The specimen nomenclature is as follows: U, control specimen; NS, specimen retrofitted using normal modulus CFRP laminates on a single side; ND, specimen retrofitted using normal modulus CFRP laminates on both sides, and HD, specimen retrofitted using ultra-high modulus CFRP laminates on both sides. The numbers after the hyphen indicate different stress ranges. The measured bond thickness varied from $0.42 \mathrm{~mm}$ to $0.60 \mathrm{~mm}$. The fatigue cycle numbers reported here were counted till final fracture happened. The cycle numbers corresponding to the low stress range for the "beach marking" technique were transferred to equivalent cycle numbers corresponding to the original stress range by Equation (1). The fatigue life extension ratio is defined as the fatigue life of a strengthened specimen divided by that of the corresponding plain welded joint.

$$
\frac{N_{1}}{N_{\mathrm{n}}}=\left(\frac{\Delta \sigma_{\mathrm{n}}}{\Delta \sigma_{1}}\right)^{m}
$$

where $N$ and $\Delta \sigma$ represent the fatigue cycle number and stress range, respectively; the subscripts 1 and $\mathrm{n}$ denote the low stress range and normal stress range, respectively; $m$ is the slope of $S-N$ curve which is taken as 3 here [44].

Table 1. Experimental program and results.

\begin{tabular}{|c|c|c|c|c|c|c|c|c|}
\hline Specimen & $\begin{array}{c}\text { CFRP } \\
\text { modulus }\end{array}$ & $\begin{array}{c}\text { Bond } \\
\text { configuration }\end{array}$ & $\begin{array}{l}\text { Stress range } \\
\quad(\mathrm{MPa})\end{array}$ & $\begin{array}{c}\text { Bond thickness } \\
\quad(\mathbf{m m})\end{array}$ & $\begin{array}{l}\text { Tested fatigue } \\
\text { cycles }(N)\end{array}$ & $\begin{array}{l}\text { Extension } \\
\text { ratio }\end{array}$ & $\begin{array}{l}\text { Predicted fatigue } \\
\text { cycles }\left(N_{\mathrm{p}}\right)\end{array}$ & $N_{\mathrm{p}} / N$ \\
\hline $\mathrm{U}-1$ & - & - & 120 & - & 146001 & 1.00 & 125720 & 0.86 \\
\hline NS-1 & Normal & Single side & 120 & 0.60 & 186884 & 1.28 & 148590 & 0.80 \\
\hline ND-1 & Normal & Double sides & 120 & 0.43 & 386525 & 2.65 & 435620 & 1.13 \\
\hline HD-1 & Ultra-high & Double sides & 120 & 0.58 & 1179410 & 8.08 & 837750 & 0.71 \\
\hline $\mathrm{U}-2$ & - & - & 153 & - & 56394 & 1.00 & 59653 & 1.05 \\
\hline NS-2 & Normal & Single side & 153 & 0.49 & 80938 & 1.44 & 73131 & 0.90 \\
\hline ND-2 & Normal & Double sides & 153 & 0.42 & 164865 & 2.92 & 198060 & 1.20 \\
\hline HD-2 & Ultra-high & Double sides & 153 & 0.52 & 460952 & 8.17 & 384290 & 0.83 \\
\hline
\end{tabular}




\subsection{Failure Mode}

\subsubsection{Specimen without CFRP Retrofitting}

For specimens without CFRP retrofitting, both of the two initial cracks propagated under the fatigue loading. Figure 4 shows a typical failed specimen (U-2) and its fracture surface. The specimen failed along one predefined notch when the crack reached a certain length while the other crack also grew to some extent. For the sake of simplicity, we call the crack which fractured as Crack 1 and the other one as Crack 2. It is easy to distinguish different regions on the fracture surface in Figure 4b, i.e., artificial notch (area A), crack propagation due to the original cyclic loading (area B), and crack propagation due to the inserted cyclic loading ( $\operatorname{area} \mathrm{C}$ ). The "beach marking" technique proved to be effective in recording crack growth with fatigue cycles. Distinct crack opening was observed for Crack 2 in Figure 4a. The specimen only failed along one notch, which may be because of the fact that the specimen was not perfectly symmetrical.

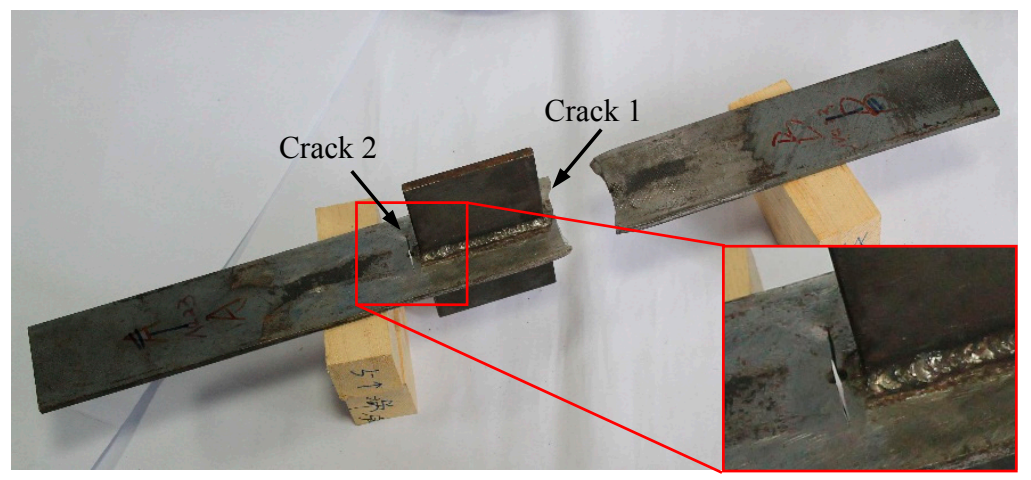

(a)

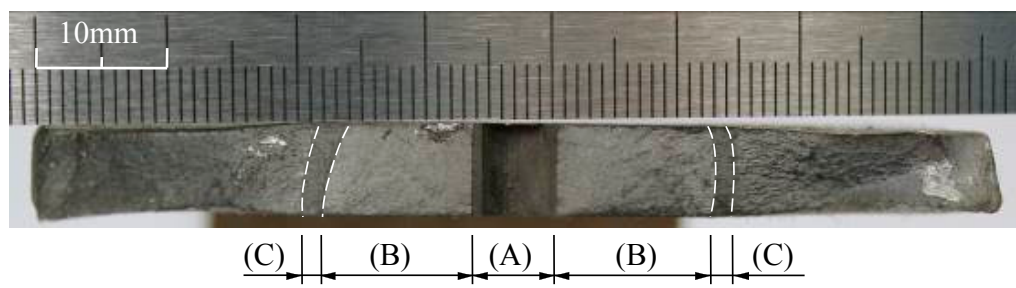

(b)

Figure 4. (a) Failed specimen U-2; (b) Fracture surface of specimen U-2 (area A: artificial notch; area B: crack propagation due to the original cyclic loading; area $\mathrm{C}$ : crack propagation due to the inserted cyclic loading).

\subsubsection{Specimen with CFRP Retrofitting}

Specimens with CFRP retrofitting also fractured along Crack 1, and Crack 2 propagated to different lengths. By comparing the crack opening of Crack 2 shown in Figures $5 \mathrm{a}$ and $4 \mathrm{a}$, it is determined that the COD value was significantly decreased in CFRP strengthened specimens, which was mainly attributed to the restraint effect offered by composite materials.

Different failure modes were observed for the specimens strengthened with CFRP laminates of different moduli. As presented in Figure 5, the specimen bonded by normal modulus CFRP laminates 
fractured with cohesive failure (adhesive layer failure) while the specimen bonded by ultra-high modulus CFRP laminates fractured with CFRP rupture. This observation conforms with a previous experimental study [8], which is related to different deformability of these two CFRP laminates.

Figure 6 shows the fracture surface of CFRP strengthened specimens. In comparison with the bare specimens, the smooth area where fatigue crack propagated steadily increased significantly. It was revealed that the bonding repair could effectively increase crack growth length and retard failure because, at the late stage of crack propagation, composite materials could help the steel element with a reduced cross-section to carry the maximum load in each cycle. The beach marks appeared to be symmetrical with the centre lines through the width of the steel plate, which implies that cracks propagated uniformly on these two sides. Furthermore, no premature failure happened during the test program. For the direction through the thickness of the steel plate, unsymmetrical beach marks were observed in specimen NS-2. Cracks grew much faster on the bare side compared to the opposite side, which clearly showed the bridge effect of composite materials.

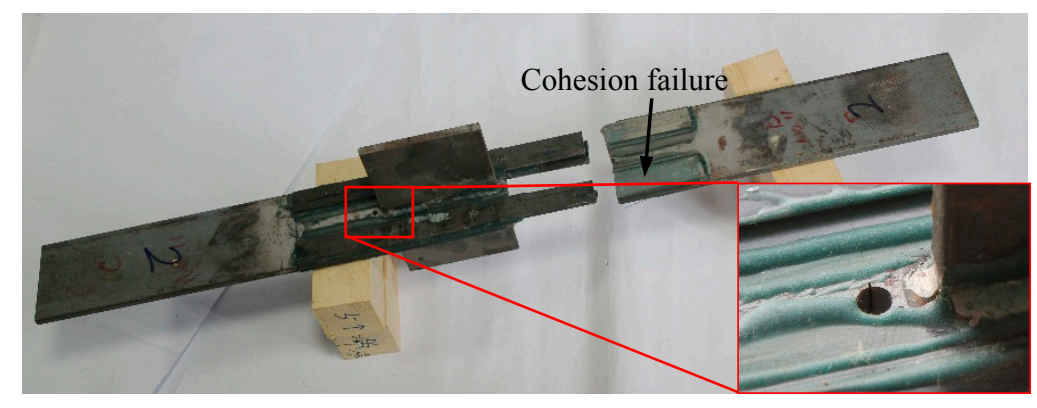

(a)

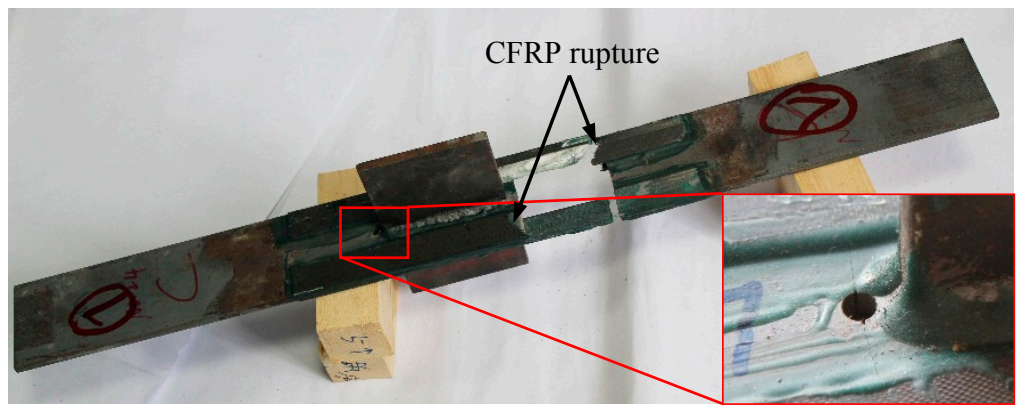

(b)

Figure 5. (a) Failed specimen ND-2 (normal modulus CFRP); (b) Failed specimen HD-2 (ultra-high modulus CFRP). 


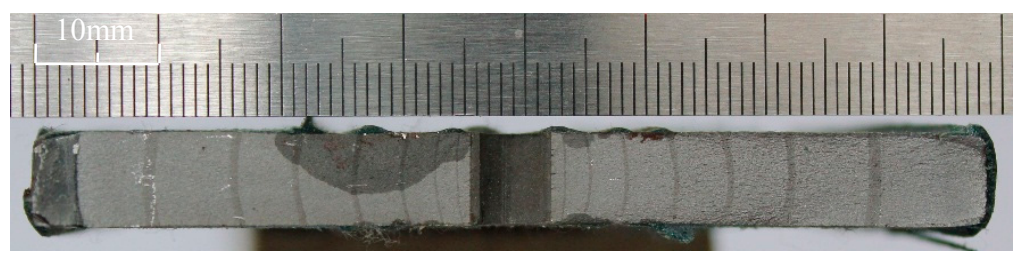

(a)

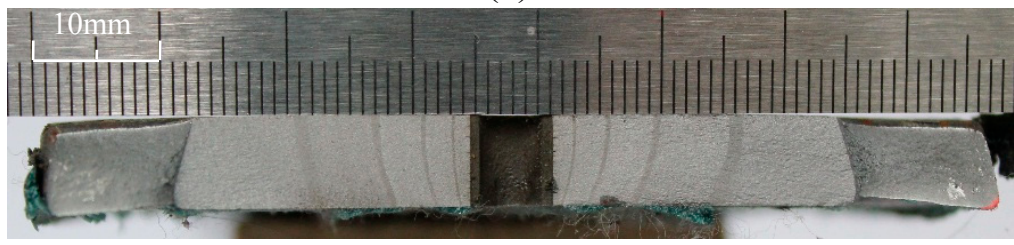

(b)

Figure 6. (a) Fracture surface of specimen ND-2 (double-sided strengthening); (b) Fracture surface of specimen NS-2 (single-sided strengthening).

\subsection{Fatigue Crack Propagation}

Fatigue crack propagation of test specimens is plotted in Figure 7 based on the beach marks shown in Figures 4 and 6. Only the cases under the stress range of $153 \mathrm{MPa}$ were selected for the sake of simplicity. Here, the horizontal axis represents the fatigue cycles " $N$ ", and the vertical axis represents half of the crack length " $a$ " (Crack 1), which was measured from the centre of the plate to the crack tip. The horizontal line where $y$ equals $40 \mathrm{~mm}$ denotes the edge the welded joints. Results showed that the final crack length before failure was remarkably extended after strengthening, especially for specimens repaired on both sides. In comparison with the bare specimen U-2, the CFRP-repaired specimens had a much shallower slope. It was, therefore, demonstrated that composite materials could effectively decrease crack propagation rate and the strengthening effect was more pronounced when double-sided repair and ultra-high modulus CFRP were adopted. It was because the composite materials helped to share the far field loading and decreased the stress field around the crack tip.

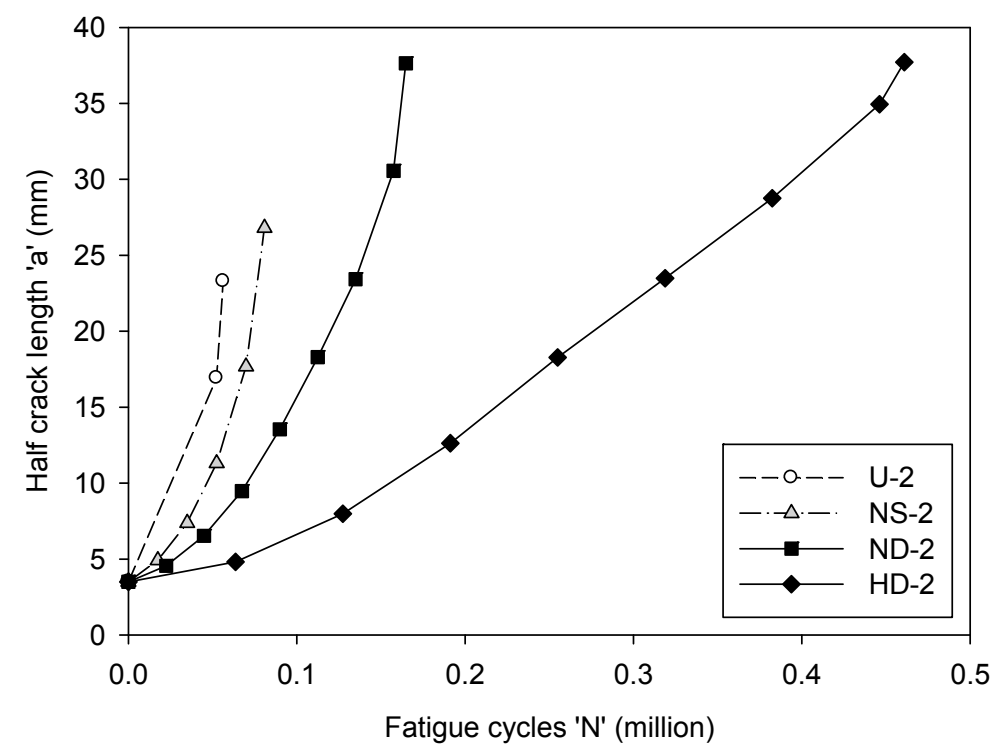

Figure 7. Crack length versus fatigue cycles. 
Like Crack 1, Crack 2 also lengthened with fatigue cycles. The crack length of control specimens was shorter than that of strengthened specimens. It was observed that all cracks in double-sided strengthened specimens had propagated underneath CFRP laminates. For single-sided bonded specimens, the crack length on the unbonded side was notably longer than that on the bonded side. After the test, the specimens were cut along Crack 2. Since it was difficult to protect the beach marks during cutting, only two fracture surfaces were obtained, as displayed in Figure 8. The corresponding fatigue crack propagation is depicted in Figure 9. The crack propagation curves of Crack 1 and Crack 2 are very close to each other. Therefore, it was concluded that the crack propagation of these two cracks was almost simultaneous and the specimen finally fractured at the cross section which was weaker. More experiments are needed to further exam the crack propagation of these two cracks. Crack propagation gauges will be used in future research to monitor the crack propagation automatically, thereby avoiding the cutting problem [8]. It is also worth comparing the fatigue behaviour of specimens with one and two initial notches.

\subsection{Fatigue Life}

The fatigue lives of all test specimens are listed in Table 1. In comparison with control specimens, the fatigue life of strengthened welded joints was prolonged by as much as 1.28 to 8.17 times, which clearly showed the effectiveness of CFRP repair. Comparisons also demonstrated the superiority of ultra-high modulus CFRP materials and double-sided strengthening. For the two stress levels adopted in this study, it was revealed that stress range was an important factor that influenced the fatigue behaviour. The test specimens' fatigue life decreased as the stress range increased. Amiri and Cavalli [45] and Tomita et al. [46] conducted experimental studies on the bending fatigue behaviour of CFRP materials and also found their fatigue life decreased with the increase of stress range. The strengthening efficiency at the high stress range (153 MPa) appeared to be slightly more pronounced compared to that at the low stress range (120 MPa) although the difference was very limited. This summary of the influence of stress on fatigue behaviour is contrary to findings reported by Monfared et al. [47], where fatigue tests on edge cracked steel plates retrofitted by CFRP were conducted and fatigue life extension ratio decreased with the increased stress range.

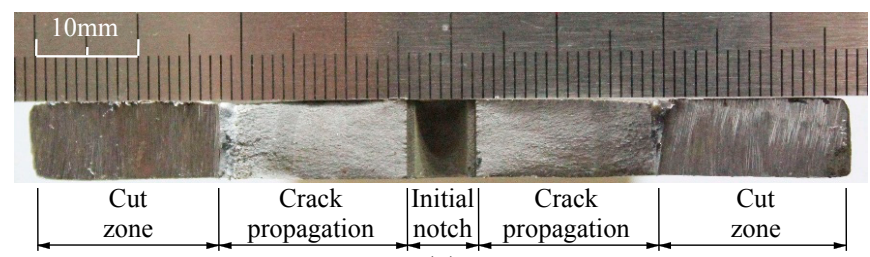

(a)

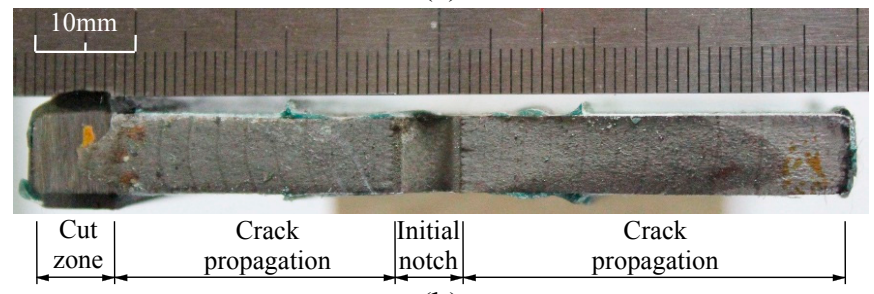

(b)

Figure 8. (a) Fracture surface of specimen U-2 (along Crack 2); (b) Fracture surface of specimen ND-1 (along Crack 2). 


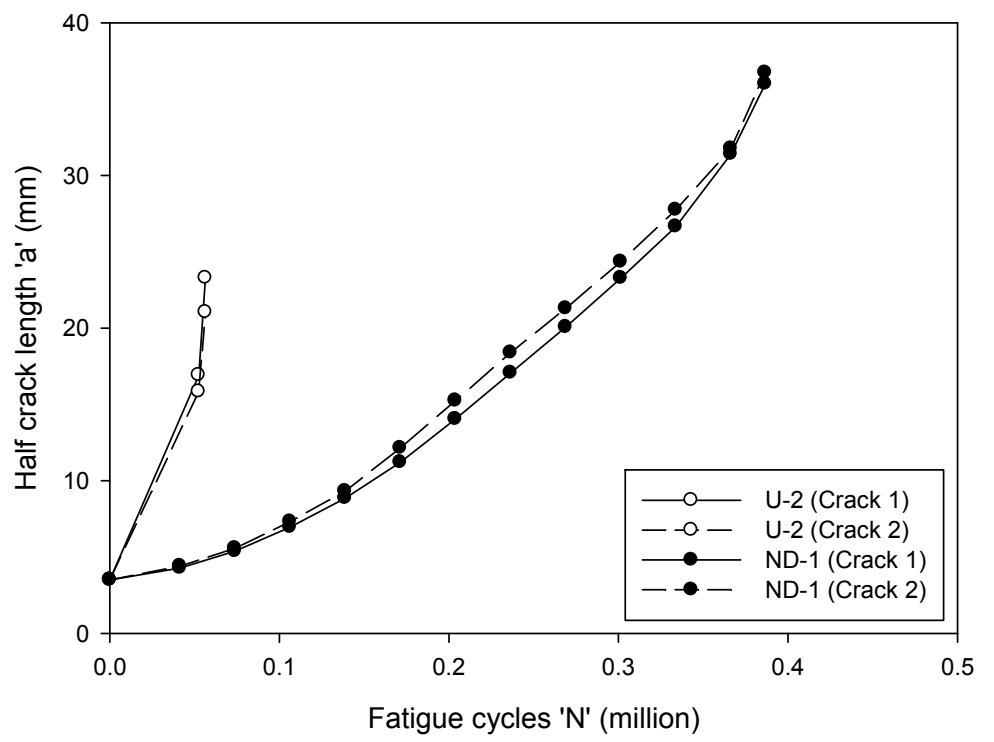

Figure 9. Comparison of fatigue crack propagation between Crack 1 and Crack 2.

For welded joints, the classification method is commonly used to assess their fatigue behaviour based on structural details, as recommended by several international standards [44,48-51]. The test results are plotted in Figure 10. Six fatigue categories, $\mathrm{C}$ to $\mathrm{H}$, were also illustrated. These categories are recommended by the Japanese Society of Steel Construction (JSSC) [51]. The inverse slope of the dashed curves was three in the finite life region. The fatigue strengths at 2 million cycles were 125, 100, 80, 65, 50 , and $40 \mathrm{MPa}$ for JSSC's C, D, E, F, G, and H categories, respectively. The constant amplitude fatigue limits for these categories were $115,84,62,46,32$, and $23 \mathrm{MPa}$, respectively. Figure 10 shows that the fatigue behaviour was significantly improved after strengthening. Bare specimens and single-sided repaired specimens approximated fell into category $G$ and the retrofitting efficiency of strengthening on a single side was limited. When normal modulus CFRP laminates were bonded on both sides, the data points were located in category F. Ultra-high modulus CFRP materials led to a more remarkable retrofitting which was equivalent to upgrading the detail from the JSSC categories F to D. The fatigue life extension ratio of repairs with ultra-high modulus CFRP was about three times that with normal modulus CFRP based on the limited test data. This was because an improved composite stiffness increased the stiffness of the specimen and decreased the stress field around the crack tip.

For the out-of-plane gusset welded joint adopted in this study, i.e., the length of the gusset plate was no more than $100 \mathrm{~mm}$ and the welding was kept in an as-welded condition, its suggested fatigue category was category F. Figure 10 implies that after damage, the fatigue behaviour was decreased to category G. The test results showed that it was feasible to recover the fatigue strength by using normal modulus CFRP bonded on both sides. However, more experimental testing and numerical simulation are needed to derive confident fatigue design categories for CFRP strengthened welded joints. 


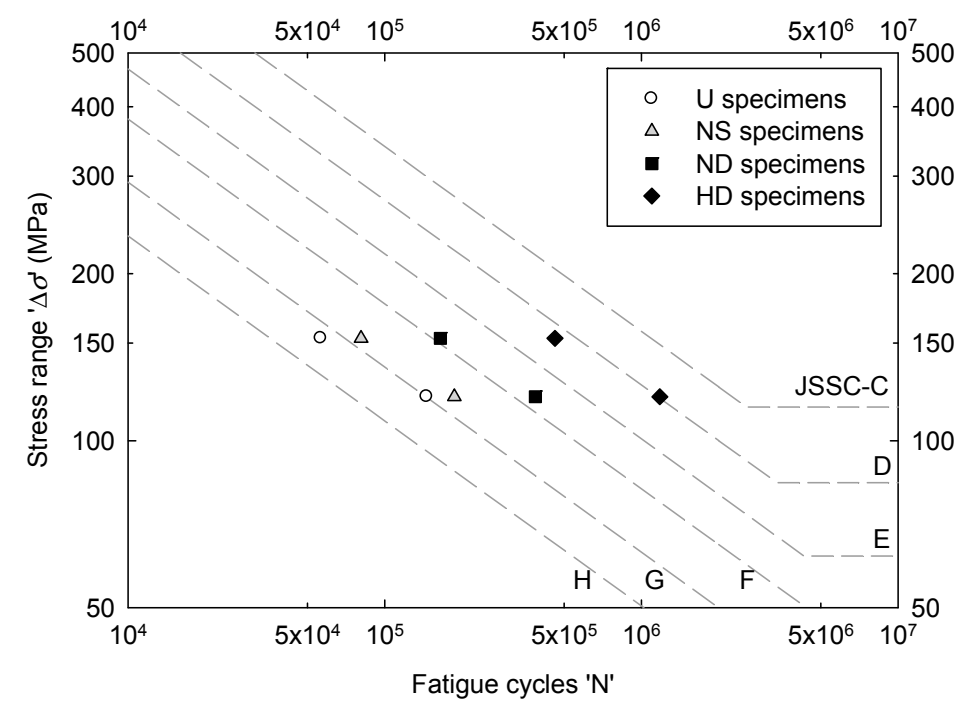

Figure 10. $S-N$ plot for test results and JSSC categories.

\section{Finite Element Modelling}

Three dimensional finite element models were developed to simulate the experimental tests. The commercial software ABAQUS (2010) was employed. The contour integral method was used to define the onset of cracking and was requested as an output parameter to calculate the SIF value. Based on the symmetrical configuration and boundary conditions, a one-eighth model was adopted for bare welded joints and double-sided strengthened specimens while a one-fourth model was adopted for single-sided strengthened specimens. The bond thickness was set at $0.5 \mathrm{~mm}$ for all the models according to the measured results given in Table 1. Symmetrical constraints were applied on the corresponding boundaries. A uniform tensile loading was applied to the end of the model. The circular hole was not modelled whereas the slot was assigned along the weld toe. It was reported by Baumgartner and Bruder [52] that the fatigue strength of stress-relieved specimens was among the same scatter as that of as-welded specimens. The influence of the residual stress cannot be clearly identified. In addition, the focus of this paper was to study the improvement of fatigue life due to CFRP strengthening on identical specimens that had the same residual stresses. Therefore, the residual stress was not taken into consideration here.

For the fatigue loading applied in the current program, materials (steel, CFRP and adhesive) were all under linear elastic stage. Therefore, the constitutive laws were set to be linear elastic. The steel plate had a Young's modulus of $227 \mathrm{GPa}$ and a Poisson's ratio of 0.3 ; the normal modulus CFRP had a Young's modulus of $166 \mathrm{GPa}$ and a Poisson's ratio of 0.3; the ultra-high modulus CFRP had a Young's modulus of $460 \mathrm{GPa}$ and a Poisson's ratio of 0.3, and the adhesive had a Young's modulus of $1901 \mathrm{MPa}$ and a Poisson's ratio of 0.36 [38].

The steel plate, adhesive layer, and CFRP laminate were all meshed using three-dimensional quadratic brick elements (C3D20R). To detect the strain singularity at the crack tip, the 20-node brick element was collapsed to a 15 -node wedge element by moving the mid-side nodes to the $1 / 4$ point of the element length, as shown in Figure 11a [53].

The detailed mesh around the crack tip is depicted in Figure 11b. A sensitivity analysis was carried out on bare welded joints to determine the ratio of the crack tip element size $l$ to crack length $a$. Two 
crack lengths, i.e., $5 \mathrm{~mm}$ and $20 \mathrm{~mm}$ were computed and the corresponding results are shown in Figure 12 (stress range of $120 \mathrm{MPa}$ ). Based on this preliminary data, it was found that the SIF values almost did not change when $l / a$ ranged from 0.025 to 0.25 . Consequently, a crack tip element size to crack length ratio of 0.1 was selected for this study.

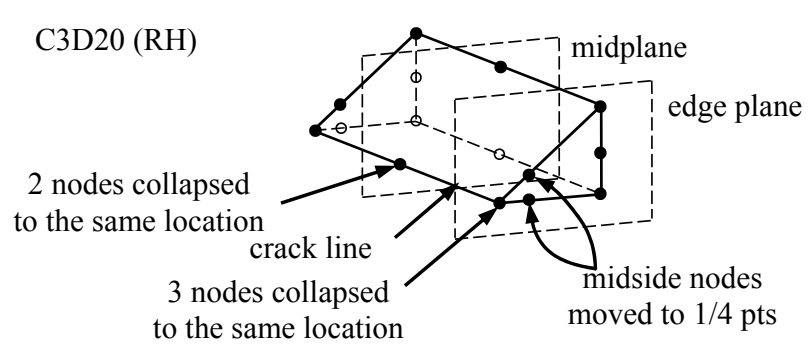

(a)

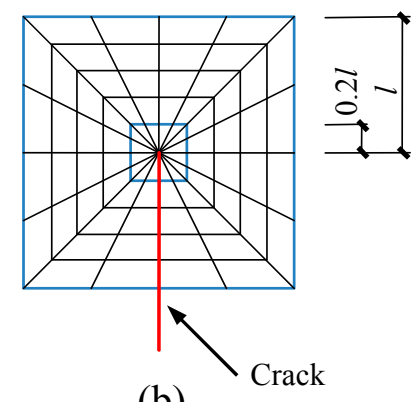

(b)

Figure 11. Collapsed three-dimensional element and crack tip mesh.

The steel plate and CFRP laminate were constrained by tying with the adhesive layer. Figure 13a illustrates a typical finite element model (double-sided strengthened specimen, $a=20 \mathrm{~mm}$ ). A previous study [54] confirmed that local debonding existed around the crack tip area due to high stress concentration. Therefore, a semi-elliptical shaped debonding area was assumed at the adhesive-steel interface for the cases where the crack had propagated underneath the CFRP laminate, as shown in Figure 14. The major semi-axis $b$ was assumed equal to the crack size within the CFRP area, and the minor semi-axis $c$ was located in a direction orthogonal to the crack. Here, the aspect ratio $c / b$ was set to be $1 / 5$ [11]. In consideration of mesh convenience, the debonding zone was modelled as displayed in Figure 13b.

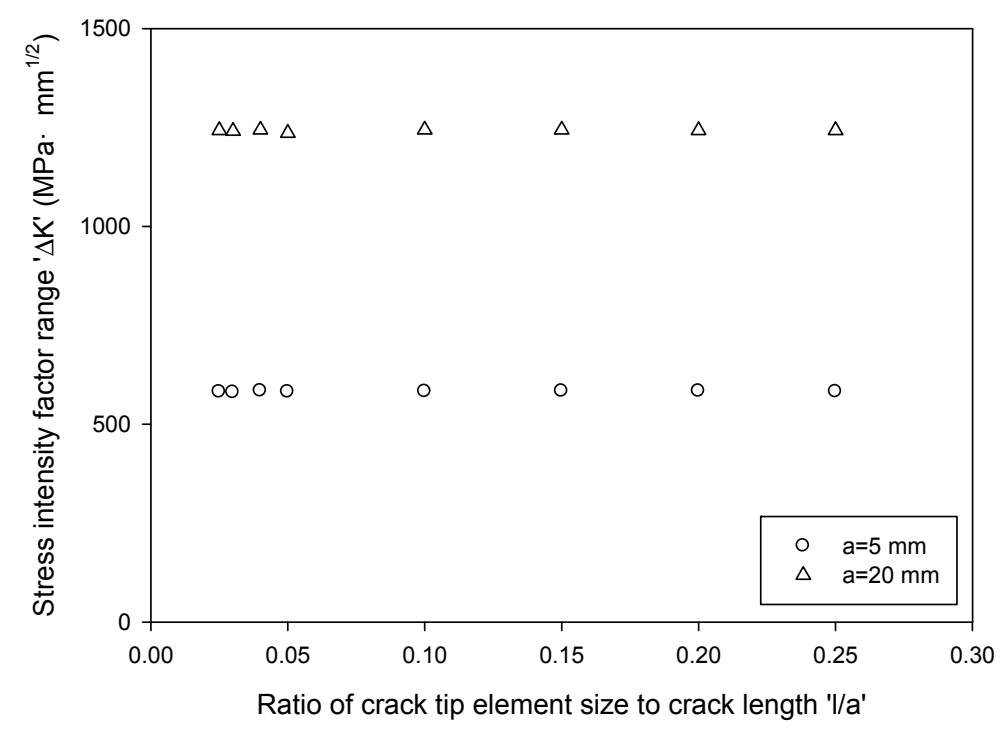

Figure 12. Stress intensity factor versus crack tip element size to crack length ratio. 


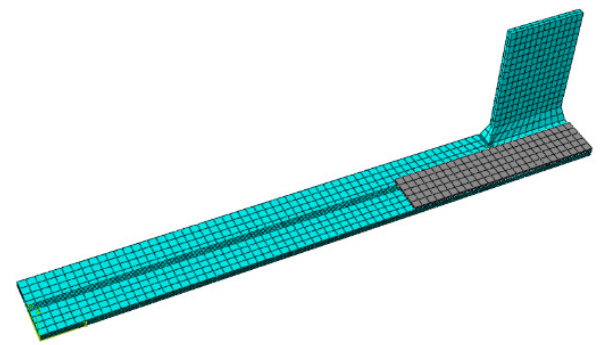

(a)

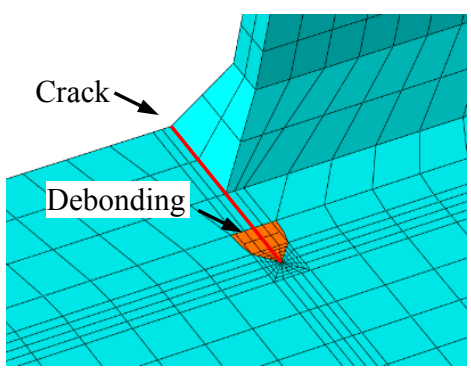

(b)

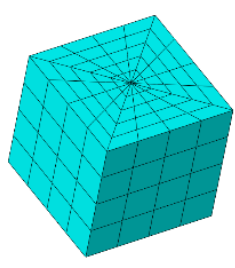

(c)

Figure 13. (a) Typical finite element model; (b) Detailed mesh in the debonding zone; (c) Detailed mesh at the crack tip.

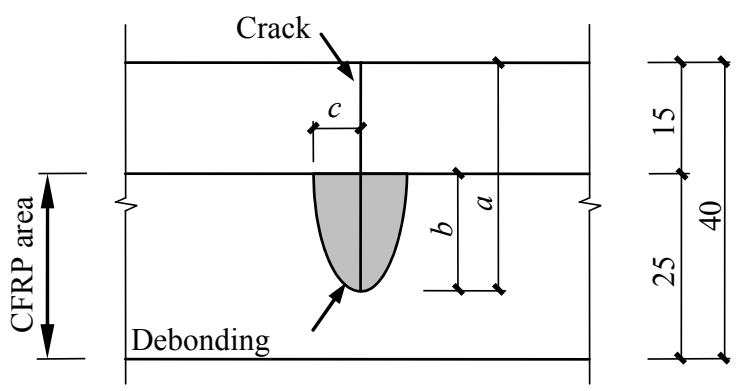

Figure 14. Debonding zone at the crack tip.

\section{Numerical Results}

\subsection{Stress Intensity Factor}

SIF values for all the cases in Table 1 with crack lengths varying from $2 \mathrm{~mm}$ to $35 \mathrm{~mm}$ were extracted from the finite element model. Since the general trend is similar, only results with reference to the stress range of $120 \mathrm{MPa}$ are given in Figure 15a. Figure $15 \mathrm{~b}$ depicts the SIF ratio with respect to different repair schemes. $\Delta K_{\mathrm{CFRP}}$ is the SIF range of a specimen strengthened with CFRP, whereas $\Delta K_{\text {joint }}$ is the SIF range of a bare welded joint. For the single-sided retrofitted specimens, secondary bending was observed from the numerical results and the SIF valued changed along the crack tip line. Therefore, the SIF value at the mid-plane was reported here. It was observed that the SIF value increased as the crack propagated. In comparison with the bare welded joints, the SIF value was significantly reduced in CFRP repaired specimens. The superiority of double-sided strengthening and ultra-high modulus CFRP was also noticed. When the crack length was $5 \mathrm{~mm}$, the SIF was declined from 582.4 $\mathrm{MPa} \cdot \mathrm{mm}^{1 / 2}$ (unpatched) to $551.9 \mathrm{MPa} \cdot \mathrm{mm}^{1 / 2}$ (normal modulus, single-sided), to $517.2 \mathrm{MPa} \cdot \mathrm{mm}^{1 / 2}$ (normal modulus, double-sided), and to $439.2 \mathrm{MPa} \cdot \mathrm{mm}^{1 / 2}$ (ultra-high modulus, double-sided) for specimens bonded by CFRP materials. The corresponding reduction percentages were about 5\%, 11\%, and $25 \%$, respectively. When the crack length reached $35 \mathrm{~mm}$, a more noticeable retrofitting effect was observed wherein the SIF values were lowered by $23 \%, 53 \%$, and $70 \%$ for specimens with normal modulus CFRP on a single side, normal modulus CFRP on both sides and ultra-high modulus CFRP on both sides, respectively. It is interesting to find that the slope of the curves in Figure $15 \mathrm{~b}$ becomes slightly steeper when the crack length is larger than $15 \mathrm{~mm}$ which indicates that the crack has propagated 
underneath the CFRP laminate. The slope change may be attributed to the constraint effect offered by the composite materials.

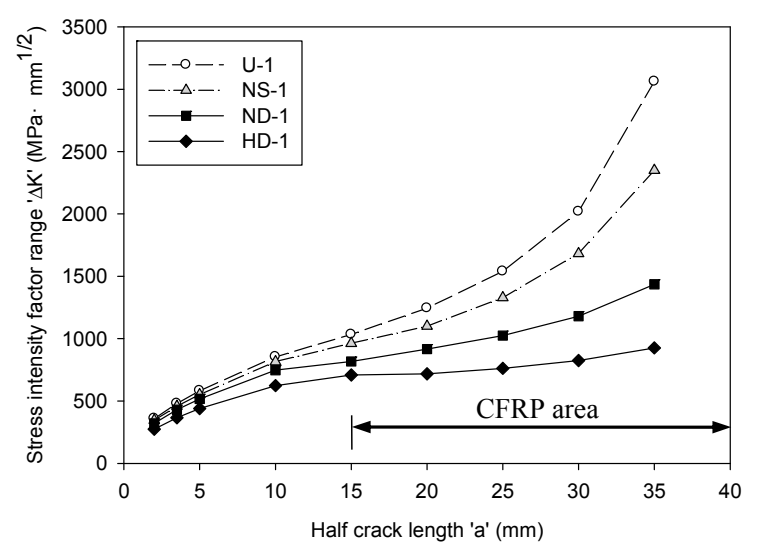

(a)

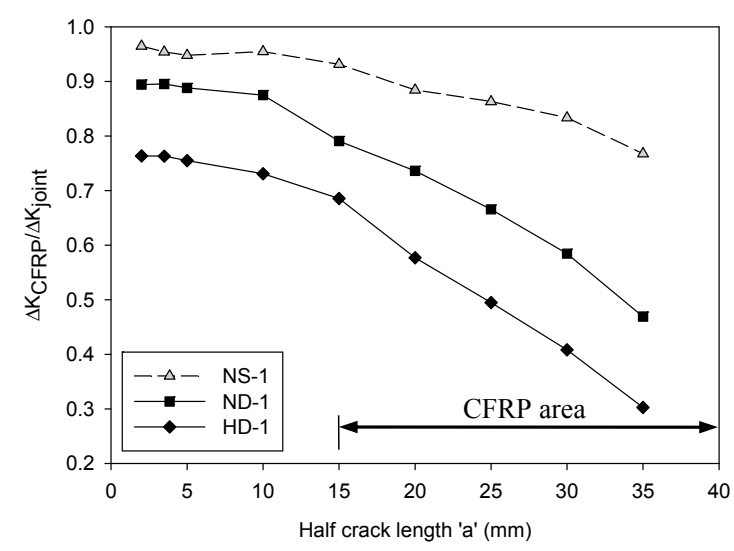

(b)

Figure 15. (a) Stress intensity factor; (b) Stress intensity factor ratio.

\subsection{Crack Opening Displacement}

Figure 16 illustrates the COD value evaluated from the numerical analysis. Half crack width versus the distance from the crack tip of the specimens with a crack length of $20 \mathrm{~mm}$ is plotted in Figure 16a. For the case with composite materials applied on a single side, the crack widths on both sides of the specimen were not equal, and therefore, both the results on the bonded side and unbonded side were reported. It is revealed that the bonding repair could effectively reduce the crack width, especially for cases where the specimens were strengthened on both sides. The effect by using ultra-high modulus CFRP was also confirmed. It should be noted that, the crack width of specimen NS-1 on the unbonded side was even larger than that of bare specimen U-1, which indicated that the retrofitting effect was partly counteracted by the eccentric effect induced by an unsymmetrical repair scheme. The COD growth with crack length is shown in Figure 16b. The COD value here represents the crack width at the edge of the one-eighth model, which developed continuously as the crack length increased. The COD value of CFRP strengthened specimens was decreased considerably, especially at the late stage of crack propagation. The COD value of specimen NS-1 on the bonded side was close to that of specimen ND-1.

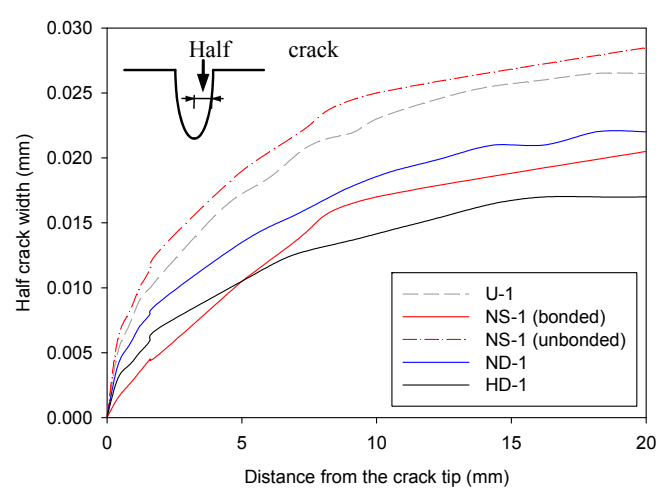

(a)

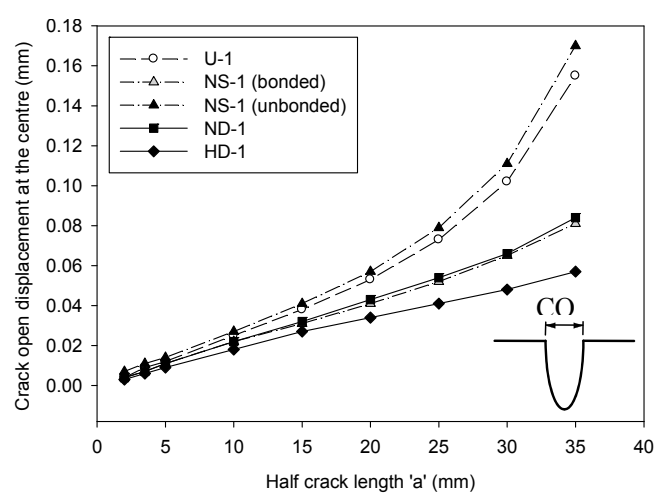

(b)

Figure 16. (a) Half crack width versus distance from the crack tip $(\mathrm{a}=20 \mathrm{~mm})$; (b) Crack opening displacement versus half crack length. 


\subsection{Fatigue Life Prediction}

The LEFM theory is adopted here to predict the fatigue behaviour. The fatigue crack propagation law based on the Paris Law is expressed by Equation (2).

$$
\mathrm{d} a / \mathrm{d} N=C\left(\Delta K^{m}-\Delta K_{\mathrm{th}}^{m}\right)
$$

where $a$ is half of the crack length, $N$ is the number of fatigue cycles, $C$ and $m$ are material constants that are determined experimentally, $\Delta K$ is the stress intensity factor range at the crack tip, and $\Delta K_{\text {th }}$ is the threshold stress intensity factor range below which the crack does not propagate.

During fatigue crack propagation life, cracks experience crack closure, which means cracks remain in a closed position even though the specimens are in tension. A crack is fully open only for a part of the load cycle [55]. It was indicated that the crack closure effect was more pronounced for CFRP strengthened specimens [11], and for single-sided repaired specimen, the crack closure effect and secondary bending effect were assumed to be counteracted [56]. Therefore, in this study, the fatigue crack propagation life of bare specimens and single-sided repaired specimens was evaluated using Equation (2), and the material constants $C$ and $m$ were taken as $6.77 \times 10^{-13}$ and 2.88 , respectively ( $\mathrm{d} a / \mathrm{d} N$ in $\mathrm{mm} /$ cycle and $\Delta K$ in $\mathrm{MPa} \cdot \mathrm{mm}^{1 / 2}$ ), as recommended by the British Standards Institution [57]. The fatigue crack propagation life of double-sided repaired specimens was estimated using Equation (3), where the stress intensity factor range $\Delta K$ was replaced by its effective range, and the material constants $C$ and $m$ were taken as $5.21 \times 10^{-13}$ and 3 , respectively $(\mathrm{d} a / \mathrm{d} N$ in $\mathrm{mm} /$ cycle and $\Delta K$ in $\mathrm{MPa} \cdot \mathrm{mm}^{1 / 2}$ ), as recommended by the International Institute of Welding [44]. The $\Delta K_{\text {th }}$ value was set as 161.8 $\mathrm{MPa} \cdot \mathrm{mm}^{1 / 2}[11]$.

$$
\mathrm{d} a / \mathrm{d} N=C\left(\Delta K_{\mathrm{eff}}^{m}-\Delta K_{\mathrm{th}}^{m}\right)
$$

where $\Delta K_{\text {eff }}$ is expressed as

$$
\Delta K_{\mathrm{eff}}=K_{\max }-K_{\mathrm{op}}=(1-q) K_{\max }
$$

where $K_{\mathrm{op}}$ is the open SIF, and $q$ is the effective stress ratio which can be calculated by

$$
q=\max \left[\frac{1}{1+p c f}\left(1+R \cdot R_{\mathrm{ys}}\right), R\right]
$$

where $R$ is the stress ratio, $R_{\mathrm{ys}}=\sigma_{\mathrm{max}} / \sigma_{\mathrm{y}}$ is the ratio of the maximum stress of applied cyclic loading to the yield stress of the steel plate, and pcf is the plastic constraint factor, which was taken as 1.68 [11].

The predicted fatigue lives of all the test specimens are plotted in Figure 17, which shows that the numerical simulation agreed well with the experimental results. The detailed data is listed in Table 1 that all the differences were less than $20 \%$ except specimen HD-1. The estimated results showed that the LEFM method based on numerical simulation was applicable for evaluating the fatigue behaviour of both bare and strengthened welded joints. 


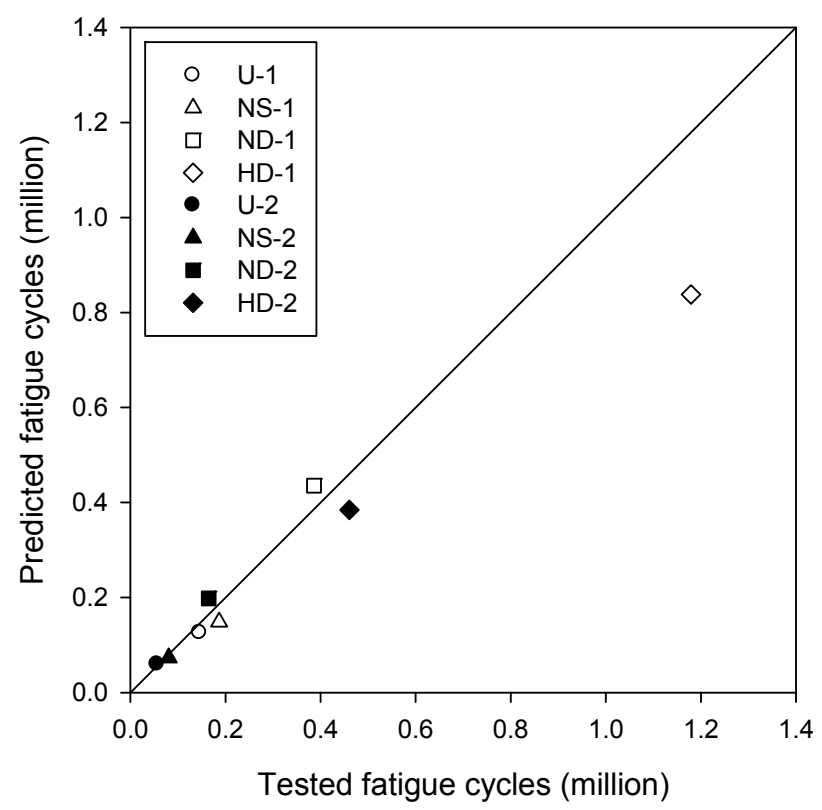

Figure 17. Fatigue life comparison between predicted results and experiential data.

\section{Conclusions}

This paper performed an experimental and numerical study on the fatigue behaviour of out-of-plane gusset welded joints strengthened with CFRP laminates. A total of eight cracked welded joints were tested under tensile fatigue loading. The SIF and COD values were calculated by finite element models. Finally, the fatigue life was predicted based on the LEFM approach. The following observations can be made and conclusions drawn.

(a) Two notches were introduced at the weld toes to simulate the initial damage. The effects of stress range, single- or double-sided strengthening and modulus of CFRP materials were investigated. It was found that both cracks propagated during the fatigue test and finally all the specimens failed along one crack. The fatigue life of repaired specimens was significantly extended compared to that of control specimens. The most efficient case was found for the specimen retrofitted by ultra-high modulus CFRP laminates on both sides under the high stress range, where the fatigue life was 8.17 times that of the corresponding bare welded joint.

(b) Finite element models were developed to assess the SIF and COD values of all test specimens. Local debonding around the crack tip at the adhesive-steel interface was considered by assuming an ideal semi-elliptical area. Numerical results demonstrated that the SIF and COD were considerably decreased after strengthening. Comparison of cases with different repair schemes and repair materials indicated a need for overlays on both sides and a higher elastic modulus to achieve a more pronounced repair efficiency. Secondary bending was observed for single-sided strengthened specimens, which implies that the repair efficiency was partly counteracted.

(c) Finally, the fatigue life was predicted based on the LEFM theory by using the SIF value extracted from numerical simulation. The predicted results showed a good agreement with the experimental data. It was, therefore, concluded that this approach was feasible to assess the fatigue behaviour of out-of-plane gusset welded joints. 


\section{Acknowledgments}

The authors wish to acknowledge the financial support of National Natural Science Foundation of China (51508406) and the National Program on Key Basic Research Project of China (973 Program) (Grant Number 2015CB057700).

\section{Author Contributions}

All authors tried their best to contribute effectively to conduct this work. Qian-Qian Yu and Tao Chen developed the experimental program with the guidance of Xiang-Lin Gu. Tao Chen and Xiang-Lin $\mathrm{Gu}$ offered materials and analysis tools. Qian-Qian Yu, Tao Chen and Ning-Xi Zhang performed the tests. Qian-Qian Yu and Tao Chen processed the data, developed the numerical models and drafted the manuscript. Tao Chen and Xiang-Lin Gu finally helped to revise the paper.

\section{Conflicts of Interest}

The authors declare no conflict of interest.

\section{References}

1. Alsayed, S.H.; Al-Salloum, Y.A.; Almusallam, T.H. Fibre-reinforced polymer repair materials-some facts. Proc. ICE Civ. Eng. 2000, 138, 131-134. [CrossRef]

2. Zhao, X.L.; Zhang, L. State-of-the-art review on FRP strengthened steel structures. Eng. Struct. 2007, 29, 1808-1823. [CrossRef]

3. Teng, J.G.; Yu, T.; Fernando, D. Strengthening of steel structures with fiber-reinforced polymer composites. J. Constr. Steel Res. 2012, 78, 131-143. [CrossRef]

4. Jones, S.C.; Civjan, S.A. Application of fibre-reinforced polymer overlays to extend steel fatigue life. J. Compos. Constr. 2003, 7, 331-338. [CrossRef]

5. Täljsten, B.; Hansen, C.S.; Schmidt, J.W. Strengthening of old metallic structures in fatigue with prestressed and non-prestressed CFRP laminates. Constr. Build. Mater. 2009, 23, 1665-1677. [CrossRef]

6. Liu, H.B.; Al-Mahaidi, R.; Zhao, X.L. Experimental study of fatigue crack growth behaviour in adhesively reinforced steel structures. Compos. Struct. 2009, 90, 12-20. [CrossRef]

7. Wu, C.; Zhao, X.L.; Al-Mahaidi, R.; Emdad, M.R.; Duan, W.H. Fatigue tests of cracked steel plates strengthened with UHM CFRP plates. Adv. Struct. Eng. 2012, 15, 1801-1816. [CrossRef]

8. Yu, Q.Q.; Zhao, X.L.; Al-Mahaidi, R.; Xiao, Z.G.; Chen, T.; Gu, X.L. Tests on cracked steel plates with different damage levels strengthened by CFRP laminates. Int. J. Struct. Stab. Dyn. 2014, 14, 1450018. [CrossRef]

9. Colombi, P.; Fava, G.; Sonzogni, L. Effect of initial damage level and patch configuration on the fatigue behaviour of reinforced steel plates. Fatigue Fract. Eng. Mater. Struct. 2015, 38, 368-378. [CrossRef]

10. Wang, H.T.; Wu, G.; Wu, Z.S. Effect of FRP configurations on the fatigue repair effectiveness of cracked steel plates. J. Compos. Constr. 2014, 18, 04013023. [CrossRef] 
11. Colombi, P.; Fava, G.; Sonzogni, L. Fatigue crack growth in CFRP-strengthened steel plates. Compos. Part B Eng. 2015, 72, 87-96. [CrossRef]

12. Liu, H.B.; Zhao, X.L.; Al-Mahaidi, R. Boundary element analysis of CFRP reinforced steel plates. Compos. Struct. 2009, 91, 74-83. [CrossRef]

13. Yu, Q.Q.; Zhao, X.L.; Chen, T.; Gu, X.L.; Xiao, Z.G. Crack propagation prediction of CFRP retrofitted steel plates with different degrees of damage using BEM. Thin-Walled Struct. 2014, 82, 145-158. [CrossRef]

14. Yu, Q.Q.; Chen, T.; Gu, X.L.; Zhao, X.L. Boundary element analysis of edge cracked steel plates strengthened by CFRP laminates. Thin-Walled Struct 2015. Submitted for publication.

15. Ghafoori, E.; Schumacher, A.; Motavalli, M. Fatigue behaviour of notched steel beams reinforced with bonded CFRP plates: Determination of prestressing level for crack arrest. Eng. Struct. 2012, 45, 270-283. [CrossRef]

16. Jiao, H.; Mashiri, F.; Zhao, X.L. A comparative study on fatigue behaviour of steel beams retrofitted with welding, pultruded CFRP plates and wet layup CFRP sheets. Thin-Walled Struct. 2012, 59, 144-152. [CrossRef]

17. Kim, Y.J.; Harries, K.A. Fatigue behavior of damaged steel beams repaired with CFRP strips. Eng. Struct. 2011, 33, 1491-1502. [CrossRef]

18. Colombi, P.; Fava, G. Experimental study on the fatigue behaivour of cracked steel beams repaired with CFRP plates. Eng. Fract. Mech. 2015. [CrossRef]

19. Ghafoori, E.; Motavalli, M. Normal, high and ultra-high modulus carbon fiber-reinforced polymer laminates for bonded and un-bonded strengthening of steel beams. Mater. Des. 2015, 67, 232-243. [CrossRef]

20. Ghafoori, E.; Motavalli, M. Lateral-torsional buckling of steel I-beams retrofitted by bonded and un-bonded CFRP laminates with different pre-stress levels: Experimental and numerical study. Constr. Build. Mater. 2015, 76, 194-206. [CrossRef]

21. Ghafoori, E.; Motavalli, M.; Botsis, J.; Herwig, A.; Galli, M. Fatigue strengthening of damaged metallic beams using prestressed unbonded and bonded CFRP plates. Int. J. Fatigue 2012, 44, 303-315. [CrossRef]

22. Ghafoori, E.; Motavalli, M.; Nussbaumer, A.; Herwig, A.; Prinz, G.S.; Fontana, M. Determination of minimum CFRP pre-stress levels for fatigue crack prevention in retrofitted metallic beams. Eng. Struct. 2015, 84, 29-41. [CrossRef]

23. Ghafoori, E.; Motavalli, M.; Nussbaumer, A.; Herwig, A.; Prinz, G.S.; Fontana, M. Design criterion for fatigue strengthening of riveted beams in a 120-year-old railway metallic bridge using pre-stressed CFRP plates. Compos. Part B Eng. 2015, 68, 1-13. [CrossRef]

24. Ghafoori, E.; Motavalli, M.; Zhao, X.L.; Nussbaumer, A.; Fontana, M. Fatigue design criteria for strengthening metallic beams with bonded CFRP plates. Eng. Struct. 2015, 101, 542-557. [CrossRef]

25. Xiao, Z.G.; Zhao, X.L. CFRP repaired welded thin-walled cross-beam connections subject to in-plane fatigue loading. Int. J. Struct. Stab. Dyn. 2012, 12, 195-211. [CrossRef] 
26. Chen, T.; Yu, Q.Q.; Gu, X.L.; Zhao, X.L. Study on fatigue behavior of strengthened non-load-carrying cruciform welded joints using carbon fibre sheets. Int. J. Struct. Stab. Dyn. 2012, 12, 179-194. [CrossRef]

27. Koller, R.E.; Stoecklin, I.; Weisse, B.; Terrasi, G.P. Strengthening of fatigue critical welds of a steel box girder. Eng. Fail. Anal. 2012, 25, 329-345. [CrossRef]

28. Koller, R.E.; Stoecklin, I.; Valet, S.; Terrasi, G.P. CFRP-strengthening and long-term performance of fatigue critical welds of a steel box girder. Polymers 2014, 6, 443-463. [CrossRef]

29. Nakamura, H.; Jiang, W.; Suzuki, H.; Maeda, K.I.; Irube, T. Experimental study on repair of fatigue cracks at welded web gusset joint using CFRP strips. Thin-Walled Struct. 2009, 47, 1059-1068. [CrossRef]

30. Wu, C.; Zhao, X.L.; Al-Mahaidi, R.; Emdad, M.R.; Duan, W.H. Fatigue tests on steel plates with longitudinal weld attachment strengthened by ultra high modulus carbon fibre reinforced polymer plate. Fatigue Fract. Eng. Mater. Struct. 2013, 36, 1027-1038. [CrossRef]

31. Wang, Z.Y.; Wang, Q.Y. Fatigue strength of CFRP strengthened welded joints with corrugated steel plate. Compos. Part B Eng. 2015, 72, 30-39. [CrossRef]

32. Chen, T.; Zhao, X.L.; Gu, X.L.; Xiao, Z.G. Numerical analysis on fatigue crack growth life of non-load-carrying cruciform welded joints repaired with FRP materials. Compos. Part B Eng. 2014, 56, 171-177. [CrossRef]

33. Chen, T.; Yu, Q.Q.; Gu, X.L.; Nie, G.H. Stress intensity factors $\left(K_{\mathrm{I}}\right)$ of cracked non-load-carrying cruciform welded joints repaired with CFRP materials. Compos. Part B Eng. 2013, 45, 1629-1635. [CrossRef]

34. Yu, Q.Q.; Chen, T.; Gu, X.L.; Zhao, X.L.; Xiao, Z.G. Boundary element analysis of fatigue crack growth for CFRP strengthened steel plates with longitudinal weld attachment. J. Compos. Constr. 2015, 19, 04014044. [CrossRef]

35. Chen, T.; Yu, Q.Q.; Gu, X.L.; Zhao, X.L. Fatigue Test on Out-of-Plane Gusset Welded Joints Strengthened with Carbon Fiber Reinforced Polymer Materials. In Proceedings of the 3rd Asia-Pacific Conference on FRP in Structures, Hokkaido, Japan, 2-4 February 2012.

36. Code for Design of Steel Structures; GB 50017-2003. China Planning Press: Beijing, China, 2003.

37. Metallic Materials_-Tensile Testing at Ambient Temperature; GB/T 228-2002. China Architecture \& Building Press: Beijing, China, 2002.

38. Fawzia, S. Bond characteristics between steel and carbon fibre reinforced polymer (CFRP) composites. PhD Thesis, Monash University, Melbourne, Australia, 2007.

39. Nguyen, T.C.; Bai, Y.; Zhao, X.L.; Al-Mahaidi, R. Mechanical characterization of steel/CFRP double strap joints at elevated temperatures. Compos. Struct. 2011, 93, 1604-1612. [CrossRef]

40. Nguyen, T.C.; Bai, Y.; Al-Mahaidi, R.; Zhao, X.L. Time-dependent behaviour of steel/CFRP double strap joints subjected to combined thermal and mechanical loading. Compos. Struct. 2012, 94, 1826-1833. [CrossRef]

41. Hollaway, L.C.; Cadei, J. Progress in the technique of upgrading metallic structures with advances polymer composites. Prog. Struct. Eng. Mater. 2002, 4, 131-148. [CrossRef]

42. Mall, S.; Ramamurthy, G. Effect of bond thickness on fracture and fatigue strength of adhesively bonded composite joints. Int. J. Adhes. Adhes. 1989, 9, 33-37. [CrossRef] 
43. Lam, A.C.C.; Cheng, J.J.R.; Yam, M.C.H.; Kennedy, G.D. Repair of steel structures by bonded carbon fibre reinforced polymer patching: experimental and numerical study of carbon fibre reinforced polymer-steel double-lap joints under tensile loading. Can. J. Civ. Eng. 2007, 34, 1542-1553. [CrossRef]

44. Recommendations for Fatigue Design of Welded Joints and Components; IIW document IIW-1823-07 ex XIII-2151-07/XV-1254-07. International Institute of Welding: Graz, Austria, 2008.

45. Amiri, A.; Cavalli, M.N. Experimental investigation of fatigue behavior of carbon fiber composites using fully reversed four point bending test. Compos. Mater. Join. Technol. Compos. 2013, 7 , 131-137.

46. Tomita, Y.; Morioka, K.; Iwasa, M. Bending fatigue of long carbon fiber-reinforced epoxy composites. Mater. Sci. Eng. A 2001, 319-321, 679-682. [CrossRef]

47. Monfared, A.; Soudki, K.; Walbridge, S. CFRP Reinforcing to Extend the Fatigue Lives of Steel Structures. In Proceedings of the 4th International Conference on FRP composites in Civil Engineering, Zurich, Switzerland, 22-24 July 2008.

48. Steel Structures; AS 4100-1998. Standards Association of Australia: Sydney, Australia, 1998.

49. Eurocode 3: Design of steel structures. Part 1-9: Fatigue; British Standards Institution: Brussels, Belgium, 2005.

50. Fatigue Design and Assessment of Steel Structures; BS 7608:1993. British Standards Institution: Brussels, Belgium, 1993.

51. Fatigue Design Recommendations for Steel Structures; Japanese Society of Steel Construction: Tokyo, Japan, 1995.

52. Baumgartner, J.; Bruder, T. Influence of weld geometry and residual stresses on the fatigue strength of longitudinal stiffeners. Weld. World 2013, 57, 841-855. [CrossRef]

53. ABAQUS, version 6.11; a software suite for finite element analysis; SIMULIA Inc: Providence, RI, USA, 2010.

54. Colombi, P.; Bassetti, A.; Nussbaumer, A. Analysis of cracked steel members reinforced by pre-stress composite patch. Fatigue Fract. Eng. Mater. Struct. 2003, 26, 59-66. [CrossRef]

55. Elber, W. Fatigue crack closure under cyclic tension. Eng. Fract. Mech. 1970, 2, 37-45.

56. Liu, H.B.; Xiao, Z.G.; Zhao, X.L.; Al-Mahaidi, R. Prediction of fatigue life for CFRP strengthened steel plates. Thin-Walled Struct. 2009, 4, 1069-1077. [CrossRef]

57. Guide to Methods for Assessing the Acceptability of Flaws in Metallic Structures; BS7910:2005. British Standards Institution: Brussels, Belgium, 2005.

(C) 2015 by the authors; licensee MDPI, Basel, Switzerland. This article is an open access article distributed under the terms and conditions of the Creative Commons Attribution license (http://creativecommons.org/licenses/by/4.0/). 